\title{
Hepatitis A Is a Health Hazard for Iranian Pilgrims Who Go to Holly Karbala: A Preliminary Report
}

\author{
Roya Ghasemian, ${ }^{1}$ Farhang Babamahmoodi, ${ }^{1}$ and Fatemeh Ahangarkani1 ${ }^{1,}$ \\ ${ }^{1}$ Antimicrobial Resistance Research Center, Department of Infectious Diseases, Mazandaran University of Medical Sciences, Sari, IR Iran \\ "Corresponding author: Fatemeh Ahangarkani, Antimicrobial Resistance Research Center, Department of Infectious Diseases, Mazandaran University of Medical Sciences, Sari, \\ IR Iran. E-mail: fkani63@gmail.com
}

Received 2016 April 01; Revised 2016 April 24; Accepted 2016 May 14.

\begin{abstract}
Background: Iraq is a highly endemic area for the prevalence of hepatitis A and annually hosts a large number of Iranian pilgrims, most of whom are susceptible to infection with the hepatitis A virus (HAV).

Objectives: This study reports the health hazard of hepatitis A for Iranian pilgrims who go to holly Karbala from the Mazandaran province.

Patients and Methods: In this cross-sectional study, the data of all patients with acute hepatitis A admitted in the Razi teaching hospital from November 23, 2014 to January 24, 2015, with a history of recently returning from holly Karbala or being exposed to Karbala pilgrims, were registered.

Results: A total number of nine patients were registered. Seven patients were male and two were female. The mean age was $30.11 \pm$ 10.09.Two patients were from the same family. All patients had typical symptoms of acute hepatitis A. None of the patients died nor did fulminant occur in any patients. In addition, all patients were treated with supportive treatment and subsequently recovered. Conclusions: This number of pilgrim patients with acute hepatitis A from a single province compels us to conduct more evaluations and follow up monitoring on all persons travelling to Karbala and be sensitive to early diagnoses of the pilgrims. In the future, it is important to be mindful of administering the HAV vaccine and Ig.
\end{abstract}

Keywords: Hepatitis A, Health Hazard, Travel, Vaccination

\section{Background}

Infection due to the hepatitis A virus (HAV) is one of the most frequent causes of viral hepatitis globally $(1,2)$. The transmission of the HAV is through direct person-toperson contact (fecal-oral transmission) and this infection can quickly be dispersed in areas with inadequate sanitation, limited access to clean water, and crowded places (3$6)$. The concentration of the virus is highest in the stool and serum. Generally, 1 - 2 weeks expired before the onset of clinical signs and symptoms (jaundice, fever, abdominal pain, and elevated levels of aminotransferase enzymes). Most patients will no longer excrete the virus in their feces by the third week of sickness. Acquiring the infection from any of the genotypes results in lifelong immunity to all strains of HAV (7). The HAV is highly endemic in some areas, such as the Middle East, Asia, Central and South America, Africa, and the Western Pacific $(8,9)$. In regions with adequate social and healthcare facilities, the main risk factor responsible for the incidence of HAV infection is population groups, including those who travel or emigrate from endemic countries. Migrants, travelers, and other mobile populations are related to small outbreaks of imported vaccine-preventable diseases such as hepatitis A by transferring these diseases from their home to the developed countries $(10,11)$. The burden of HAV infections has decreased in Iran during recent years due to improvements in health and sanitation (12). The majority of Iranian Shiite Muslims who visit the holy cities of Iraq have never been exposed to HAV infection and so are not immune to it. Iraq has seen many wars over the past decades and its infrastructure has been destroyed-a fact that affects the rate of orally transmitted infections. Iraq is a highly endemic area for this infection; therefore, Iranian pilgrims are susceptible to become infected with the HAV (3). Extreme hot climate, crowded accommodations, limited access to improved water sources, and limited access to sanitation facilities encourage the transmission of the HAV among pilgrims. The advanced age of many pilgrims adds to the morbidity and mortality risks (13). HAV infections can be an expensive burden in terms of both direct medical costs and loss of productivity. An HAV infection may require several days or weeks of hospitalization and may cause absenteeism from work for several weeks or months. Traveling from high to lower endemicity areas of the HAV infection may portend an increased public health burden and bring 
about a shift in infection to older individuals, which will result in increased morbidity and mortality. All of these costs are preventable by vaccination, thereby providing immunity to the infection $(12,14,15)$. To the best of our knowledge, this is the first report on the outbreak of the hepatitis A infection in a group of Iranian pilgrims returning from holly Karbala.

\section{Objectives}

This study reports the health hazard of hepatitis A for Iranian pilgrims who go to holly Karbala from the Mazandaran province.

\section{Patients and Methods}

The data of all patients with acute hepatitis A infection admitted in the Razi teaching hospital from November 23, 2014 to January 24, 2015, with the history of recently returning from holly Karbala, were registered. For each patient, the data collected included demographic features such as sex, age, sanitation condition, living place, potential for exposure to a person with hepatitis A infection, and history of traveling to an endemic area of hepatitis A infection. Diagnosis of hepatitis A infection was made by the presence of: prodromal symptoms and jaundice, a 10-fold rise in serum aminotransferase level at any time during the course of the disease, serologic evidence of an acute HAV infection (antiHAV IgM test), and history of traveling to Karbala during the last 45 days. Information was extracted with prior permission from the patients' records

\section{Results}

In November 2014, over a period of less than three months, a total number of nine patients with manifestations suggestive of an acute viral hepatitis A infection were referred and admitted to the Razi teaching hospital. The patients shared no common exposures except the history of traveling to Karbala or contact with Karbala pilgrims. Hepatitis B and C serology tests were negative. Testing for anti-HAV IgM was positive and confirmed the presence of acute or recent hepatitis A infection. Demographic features for each patient, such as sex, age, sanitation condition, living place, potential for exposure to a person with hepatitis A infection, and history of traveling to an endemic area of hepatitis A infection are shown in Table 1. Seven patients were male and two were female. The mean age was $30.11 \pm 10.09$ (ranging between 19 and 49). Seven patients were Karbala pilgrims and two were the family members of Karbala pilgrims. Patients number 2 and 5 were brothers. Even though they had thalassemia, they did not regularly receive blood. None of the patients had a history of suffering from hepatitis B and C concomitantly. Patient number 5 was infected by hepatitis A 27 days after exposure to his brother who was infected with hepatitis $\mathrm{A}$, and both patients recovered without complications. All the patients had typical symptoms, such as prodrome and progressive jaundice. Laboratory examinations indicated high levels of bilirubin [average: 14.95 (range 3.8 - 34)], ALT [average: 1755 (range 90 - 5200)], and AST [average: 770.4 (range 80 - 2200)]. Three patients developed severe liver disease. PT was normal in six patients and was abnormal in three patients. PT for one patient was $30 \mathrm{~s}$. None of the patients died nor did fulminant occur in any patients. All patients were treated with supportive treatment and recovered.

\section{Discussion}

Hepatitis A infection is a health problem in communities in which the immune levels are changing from hyperendemic to the intermediate and lower endemic levels. Studies have shown nearly no incidences of HAV infection throughout different regions of Iran; hence, Iran is generally considered to be a low endemic area (16), although certain regions may be intermediate or hyperendemic. In fact, in these areas, a large number of susceptible individuals reside such that, when confronted with the HAV, they will most likely acquire an acute infection that may lead to the development of a severe form of the disease in these populations and in vulnerable age groups (17). In highly endemic areas, young children are the most frequently affected population and, in developed countries, one of the majority groups of symptomatic cases occurs among adolescents. The prevalence of the hepatitis A antibody in the general US population was 31.3\%, ranging from 9.4\% among individuals aged 6 - 11 years. Most hepatitis A outbreaks occur in children, adolescents, and young adults who live in intermediately endemic communities; these epidemics tend to move from community to community over time. In the United States, a study assessed the economic burden of hepatitis A infection in adolescents and adults considering the costs of symptomatic infection (including drugs, therapy for fulminant disease, hospitalization, physician visits, diagnostic studies, and liver transplantation), morbidity (loss of income from missed work and loss of ability to perform housekeeping activities), and mortality. The annual cost of hepatitis A infection that resulted from this analysis was estimated at $\$ 488.8$ million $(18,19)$. In our previous study in Sari, it was concluded that in the age group of 15 - 17 years, $47.5 \%$ of people in urban regions are immune to HAV (20). Therefore, approximately $50 \%$ of the 
Table 1. Demographic Data for Pilgrims With Hepatitis A Infection Returning From Karbala

\begin{tabular}{|c|c|c|c|c|c|c|c|}
\hline Case & Sex & Age & Living Place & Occupation & Exposure to a Person With Hepatitis A & History of Traveling to Karbala & Treated Water \\
\hline $\mathbf{1}$ & M & 49 & $\mathrm{U}$ & Self-employed & - & + & + \\
\hline 2 & M & 29 & $\mathrm{R}$ & Shopkeeper & - & + & + \\
\hline 3 & $\mathrm{~F}$ & 19 & $\mathrm{U}$ & Housekeeper & + & - & + \\
\hline 4 & M & 35 & $\mathrm{U}$ & Self-employed & - & + & + \\
\hline 5 & M & 23 & $\mathrm{R}$ & Shopkeeper & + & - & + \\
\hline 6 & M & 35 & $\mathrm{R}$ & Topographer & - & + & + \\
\hline 7 & M & 31 & $\mathrm{U}$ & Clergyman & - & + & + \\
\hline 8 & $\mathrm{~F}$ & 30 & $\mathrm{U}$ & Housekeeper & - & + & + \\
\hline 9 & M & 26 & $\mathrm{R}$ & Worker & - & + & + \\
\hline
\end{tabular}

Abbreviations: F, female; M, male; R, rural; U, urban.

urban population is susceptible to HAV when they travel to endemic areas, such as Zabol in the south of Iran which has a $90 \%$ endemicity rate, or to pilgrimage places such as Karbala $(3,21)$. Traveling to these areas can lead to a severe outbreak of infection with the HAV associated with fulminant among pilgrims. Following the war with the United States, post-war Iraq has become a hyperendemic area of the HAV due to poor socioeconomic conditions and lack of proper sanitation (3). Hence, when traveling to Karbala, at least one Iranian pilgrim will probably not have a history of hepatitis A, and therefore will not have immunity, which can consequently lead to an outbreak of hepatitis A infection among the pilgrims. Because most Iranian pilgrims are more than 30 years old and live in large-sized families, the risk of severe infection and fulminant is notable (22).

Four of the nine patients lived in rural locations and were 23 - 35 years old. Seven patients had a history of traveling to Karbala and two had contact with pilgrims with HAV infections. One patient suffered from a severe form of the disease after coming into contact with his brother who had returned from Karbala with the hepatitis A infection approximately one month previously. Fortunately, he was cured with supportive treatment. In our study, two patients were family members; therefore, it is important to increase the public's awareness about contagion of the $\mathrm{HAV}$, especially among family members. Due to the lack of access to vaccines and immunoglobulin for prevention of the disease, the best approach is to use serological studies and other background checks for this disease among pilgrims traveling to Karbala or other endemic areas. The populace should be educated about the hygienic aspects of food and fluid intakes. The epidemiologic transition of the $\mathrm{HAV}$, clearly shows the need for new strategies for controlling this infection in the community, as well as preventive measures for passengers, especially in high-risk groups. Based on the findings of many studies, the Iranian people are susceptible to infection by hepatitis A, and ultimately, HAV vaccinations should be offered $(7,15,23,24)$. HAV vaccination is an effective means to decrease the spread of HAV in the community and subsequently prevent HAV outbreaks (24) Vaccination of high-risk groups and travelers to endemic areas, especially Karbala, is strongly recommended to prevent HAV infections $(25,26)$. Knowledge of the elevated numbers of patients with acute hepatitis A from a single province forces us to conduct evaluations and follow up monitoring on pilgrims who travel to Karbala in order to achieve an early diagnosis. In the future, vaccination for the HAV and administration of Ig must be considered.

\section{Footnotes}

Authors' Contribution: Study design, visiting patients, acquisition of data, writing of the paper: Roya Ghasemian, acquisition of data, visiting patients: Farhang Babamahmoodi, study design, acquisition of data, writing of the paper, critically reading the manuscript: Fatemeh Ahangarkani.

Conflict of Interest: The authors declare that they have no competing interests.

\section{References}

1. Mahboobi N, Alavian SM. Hepatitis A in the Eastern Mediterranean region: a review on the prevalence. Scimetr. 2013;2(1).

2. Alavian SM. Hepatitis A. Aust Fam Physician. 2011;40(4):185. [PubMed: 21744525]

3. Alavian SM. Iraq: A Hot Zone for HAV Infection?. Hepat Mon. 2005;5(3):53-6. 
4. Mahboobi N, Porter SR, Karayiannis P, Alavian SM. Oral fluid and hepatitis A, B and C: a literature review.JOral Pathol Med. 2012;41(7):505-16. doi: 10.1111/j.1600-0714.2011.01123.x. [PubMed: 22188507].

5. Karimi Elizee P, Alavian SM, Miri SM, Behnava B, Alavian SH, Keshvari $\mathrm{M}$, et al. The seroprevalence of entrically transmitted viral hepatitis in hcv infected thalassemia and hemophilia patients in iran. JundishapurJ Microbiol. 2013;6(7).

6. Salahei M, Ansari Moghaddam A, Sanei Moghaddam E, Khosravi S, Hajibeigi B, Alavian SM. The epidemiological pattern of acute viral hepatitis in Tehran and Zahedan: A comparison study. Gastroenterol Hepatol Bed Bench. 2009;3(1).

7. Ghorbani GA, Mahboobi N, Lankarani KB, Alavian SM. Hepatitis A Prevention Strategies, Haiti Case: Should Rescuers Be Immunized. Iran Red Crescent Med J. 2010;2010(3):221-3.

8. Mahboobi N, Safari S, Alavian SM. Hepatitis A virus in Middle East countries: More evidence needed. Arab J Gastroenterol. 2010;11(1):1-2.

9. Alavian SM. Hepatitis a in developed country, the result should interpret carefully. Gut Liver. 2011;5(3):395-6. doi: 10.5009/gnl.2011.5.3.395. [PubMed: 21927674].

10. Gushulak BD, MacPherson DW. Globalization of infectious diseases: the impact of migration. Clin Infect Dis. 2004;38(12):1742-8. doi: 10.1086/421268. [PubMed: 15227621].

11. Bonanni P, Boccalini S, Bechini A, Eurohep Net Team . Measurement and reporting of burden of disease for hepatitis A: results of the EUROHEP.NET feasibility survey. Eur J Public Health. 2007;17(1):69-74. doi: 10.1093/eurpub/cklo88. [PubMed: 16793836].

12. Ghorbani GA, Alavian SM, Assari S. Seroepidemiology of hepatitis A virus in Iranian soldiers in 2006: do they need vaccination. Hepat Mon. 2007;7(1):7-9.

13. Ahmed QA, Arabi YM, Memish ZA. Health risks at the Hajj. The Lancet. 2006;367(9515):1008-15.

14. Fiore AE, Wasley A, Bell BP. Advisory Committeee on Immunization Practices (ACIP). Prevention of hepatitis A through active or passive immunization: recommendations of the Advisory Committee on Immunization Practices (ACIP). MMWR Morb Mortal Wkly Rep. 2006;55:123.

15. Alavian SM. Vaccination in Health Care Workers Should be Following in our Country Now?!. Iran Red Crescent Med J. 2013;15(12):17145. doi: 10.5812/ircmj.17145. [PubMed: 24693406].
16. Merat S, Rezvan H, Nouraie M, Abolghasemi H, Jamali R, AminiKafiabad S, et al. Seroprevalence and risk factors of hepatitis A virus infection in Iran: a population based study. Arch Iran Med. 2010;13(2):99104. [PubMed: 20187662].

17. Ramezani H, Bozorgi SH, Nooranipour M, Mostajeri A, Kargar-Fard $\mathrm{H}$, Molaverdikhani S, et al. Prevalence and risk factors of hepatitis A among blood donors in Qazvin, central Iran. Singapore Med J. 2011;52(2):107-12. [PubMed: 21373737].

18. Rosenthal P. Cost-effectiveness of hepatitis A vaccination in children, adolescents, and adults. Hepatology. 2003;37(1):44-51. doi: 10.1053/jhep.2003.50016. [PubMed:12500187].

19. Dinelli MI, Fisberg M, Moraes-Pinto MI. Anti-hepatitis A virus frequency in adolescents at an outpatient clinic in Sao Paulo, Brazil. Rev Inst Med Trop Sao Paulo. 2006;48(1):43-4. [PubMed: 16547579].

20. Alian S, Ajami A, Ghasemian R, Yadegarinia D. Age-specific seroprevalence of hepatitis A in Sari, northern Islamic Republic of Iran. East Mediterr Health J. 2011;17(10):754-8. [PubMed: 22256409].

21. Salehi M, Sanei M. Hepatitis A seroepidemiology in under 30 years old population. J Guilan M Sci. 2005;10:37-8.

22. Moschen ME, Floreani A, Zamparo E, Baldo V, Majori S, Gasparini V, et al. Hepatitis A infection: a seroepidemiological study in young adults in North-East Italy. Eur J Epidemiol. 1997;13(8):875-8. [PubMed: 9476815].

23. Hesamizadeh $K$, Sharafi $H$, Keyvani $H$, Alavian SM, Najafi-Tireh Shabankareh A, Sharifi Olyaie R, et al. Hepatitis A Virus and Hepatitis E Virus Seroprevalence Among Blood Donors in Tehran, Iran. Hepat Mon. 2016;16(1):32215. doi: 10.5812/hepatmon.32215. [PubMed: 27110256].

24. Rezaee-Zavareh MS, Karimi-Sari H, Dolatimehr F, Alavian SM. Hepatitis A Virus Infection, Vaccination and Iranian Healthcare Workers. Hepat Mon. 2015;15(12):35238. doi: 10.5812/hepatmon.35238. [PubMed: 26977171].

25. Elizee PK, Alavian SM. Prevention of hepatitis a virus infection, need to vaccinate or not?. Int JPrev Med. 2013;4(8):863-5. [PubMed: 24049610].

26. Izadi M, Esfahani AA, Hassannia H, Jonaidi Jafari N, Rahmati Najarkolaei F, Rezaee-Zavareh MS. Seroprevalence of hepatitis A virus among Iranian soldiers. Gastroenterol Hepatol Bed Bench. 2016;9(2):100-4. [PubMed: 27099669]. 